\title{
Occupational Exposure to Respirable Suspended Particulate Matter and Lung Functions Deterioration of Steel Workers: An Exploratory Study in India
}

\author{
Lakhwinder Pal Singh, ${ }^{1}$ Arvind Bhardwaj, ${ }^{1}$ and Kishore Kumar Deepak ${ }^{2}$ \\ ${ }^{1}$ Department of Industrial \& Production Engineering, Dr. B. R. Ambedkar National Institute of Technology, Jalandhar, \\ Punjab 144044, India \\ ${ }^{2}$ Department of Physiology, All India Institute of Medical Science, New Delhi, India
}

Correspondence should be addressed to Lakhwinder Pal Singh; singhl@nitj.ac.in

Received 14 May 2013; Accepted 1 July 2013

Academic Editors: V. H. Borja-Aburto and I. Szadkowska-Stanczyk

Copyright ( 2013 Lakhwinder Pal Singh et al. This is an open access article distributed under the Creative Commons Attribution License, which permits unrestricted use, distribution, and reproduction in any medium, provided the original work is properly cited.

Objective. Manufacturing industry, especially casting and forging (iron and steel) industry, comprises a major part of the occupation in India. However, health protection is still ignored. Therefore the present study explores the respiratory symptoms among steel workers and subsequently measured the level of exposure to RSPM and lung functions parameters using spirometry investigation. Method. Present study assessed the level of respiratory symptoms through questionnaire survey of 572 workers, out of which 309 workers and another control group of 74 subjects were assessed for the spirometry test. Both of the groups were statistically matched for age and BMI. Students' $t$-test and one-way ANOVA were used to compare the various subgroups. Results. The results reveal that workers are exposed to higher respirable suspended particulate matter (RSPM) levels than the limit of $5 \mathrm{mg} / \mathrm{m}^{3}$ prescribed by Indian factory act. The spirometric parameters such as $\mathrm{FVC}, \mathrm{FEV}_{1}, \mathrm{FEV}_{1} / \mathrm{FVC}$ ratio, $\mathrm{FEF}_{25-75}, \mathrm{PEFR}, \mathrm{PIFR}$, and FIVC were significantly lower in exposed group than in controls. In the present scenario the iron and steel SMEs of the region are very much lagging behind in implementing the occupational health and safety practices. Conclusions. The majority of the workers were not wearing proper PPEs like masks due to ergonomically bad design, and at the same time they were working 60 to $72 \mathrm{hrs} /$ week, which leads to very high level of exposure to RSPM. Therefore, the workers were under higher risk of lungs functions deterioration.

\section{Introduction}

A number of studies have been reported with respect to occupational dust exposure and respiratory health. Chen et al. [1] reported that the average respirable dust exposure was found to decrease the forced vital capacity (FVC) and forced expiratory volume in one second $\left(\mathrm{FEV}_{1}\right)$ in smoking workers. Neaimi et al. [2] explored that a percentage of the exposed workers reported recurrent and prolonged cough, phlegm (25\%), wheeze, and bronchitis, shortness of breath, bronchial asthma. Ventilatory function (FVC, $\mathrm{FEV}_{1}, \mathrm{FEV}_{1} / \mathrm{FVC}$, and PEF) was significantly lower in the exposed workers compared with unexposed workers. In another cross-sectional study, the quartz stone workers exposed to approximately $100 \%$ free silica were found to have deteriorated lung function which could be attributed mainly to respiratory disorders along with other epidemiological factors such as sex, age, duration of exposure, and smoking [3]. Koo et al. [4] reported that mean values for all ventilatory indices except FVC in foundry workers were significantly lower than those in control subjects. The increasing exposure to silica dust is associated with progressive deterioration in ventilatory function of an obstructive nature [4]. In another study in Hong Kong, Law et al. [5] reported that silica dust exposure in the construction industry is a major cause of silicosis. The effect of occupational silica exposure on pulmonary function resulted in a consistent association between increased pulmonary function abnormalities and estimated measures of cumulative silica exposure within the current allowable OSHA regulatory level [5]. 
In one of the studies by Law et al. [5] they indicated that silica dust exposure in the construction industry is the major cause of silicosis in Hong Kong. The job processes of caisson work and stone splitting were particularly high risk [5]. In a cross sectional and longitudinal (seven-year) survey of workers in a copper refinery was carried out from medical questionnaires, chest radiographs, and spirometry. The prevalence of chronic obstructive pulmonary diseases (COPD) (forced expiratory volume in one second $\left(\mathrm{FEV}_{1}\right)<80 \% /$ predicted $)$ was $5 \%$, small airway dysfunction (SAD) (maximal midexpiratory flow $(\mathrm{MMEF})<60 \%$ predicted) was $7 \%$, and this did not differ from the control population [6].

Various studies reported lower FVC, $\mathrm{FEV}_{1}, \mathrm{FEV}_{1} / \mathrm{FVC}$ ratio, PEFR, and PIFR [4, 7-9]. The lowering in FVC, $\mathrm{FEV}_{1}$, and $\mathrm{FEV}_{1} / \mathrm{FVC} \%$ suggests a combination of obstructive and restrictive patterns in their lungs. The lowering in $\mathrm{FEF}_{25-75}$ also causes an airway obstruction as it gives an indication of what is happening in the lower airways. The decrease in PEFR, and PIFR is an indicator of restrictive lung disease. In another study by Singhal et al. [10] have also reported a significant reduction in expiratory and inspiratory flow rates, that is, PEFR, PIFR, $\mathrm{FEF}_{25-75}$, and $\mathrm{FIF}_{50}$. Reduction in PEFR otherwise showed a classic pattern of restrictive lung disease. The flow rates at low volumes, that is, $\mathrm{FEF}_{25-75}$ and $\mathrm{FIF}_{50}$, indicates flow rates in small airways, that is, those with internal diameters of less than $2 \mathrm{~mm}$. These are reduced at low lung volumes both in restrictive and obstructive diseases. Tiwari et al. [3] reported that lung function measurements, even after adjusting for age, weight, and smoking habits, were significantly lower in the silica dust exposure group than in the control group. Mikov [11] showed that the mean FEV of foundry workers was considerably lower than that of a control group irrespective of the smoking habit.

Manufacturing industry comprises a major part of the occupation in India. In apprehension of unemployment, the workers have accepted the jobs with low resources settings including health and safety consideration. The other researchers reported the respiratory symptoms and lung impairment among the workers exposed to the occupational dust/gasses and chemicals. Most of these studies were carried out in developed countries, whereas in Indian SMEs especially the casting and forging industry, very limited literature is available on occupational health and safety issues. Therefore, it is very essential to assess the level of RSPM exposure in these units and subsequently to investigate the level of lung functions deterioration.

\section{Material and Methods}

This study included small and medium scales (SMEs) casting and forging units located in northern India. Since, the approachability to the management of the organization and their willingness to participate in the study were more of concern than randomization as work conditions of most casting and forging units in this region are almost similar, nonprobability convenience sampling was used to select SMEs and subjects. The study has been conducted involving 572 workers. A standardized, self-reporting questionnaire was used and interviews were conducted. The questionnaire included use of protective equipments and awareness of benefits of PPEs, respiratory symptoms, and so forth. The questions included demographic information, occupational history, past medical history, use of drugs, respiratory symptoms (cough, wheezing, breathlessness, phlegm), asthma history, smoking habits, and allergies. The questionnaire was pretested before it was used to assess the information. As workers of these units were mostly illiterate or less educated, statements of the questionnaire were translated to local language of the state, that is, Punjabi/Hindi, and responses were entered in questionnaire.

2.1. Subjects. The study included two groups of population, one group of 309 male subjects (workers) from casting and forging industries and another group of control 74 nonexposed male subjects. For including workers, a formal permission was obtained from the managements of the casting and forging units. These workers belonged to a common industrial environment where casting and forging activities were carried out, and the workers were engaged in different work areas like moulding, molten metal pouring, grinding, forging, punching, blanking, welding, gas cutting, and so forth. Here again, nonprobability convenience sampling was the criterion of selection of the subjects. The subjects of both the groups were requested to voluntarily participate in the study. An informal consent was taken from each volunteer. They were educated about the test and were requested for reporting to the laboratory. The subjects from the industry were transported from their work place to institute's Ergonomics Laboratory. After the test, each subject was compensated through a token money for sparing their time and they were again transported to their respective work places.

2.2. Data Acquisition and Protocol. The subjects of both the groups were brought to institute's Ergonomics laboratory for subjects' demographic profile (age, height, weight, and work experience), details of alcohol intake, and spirometry test. RMS Helios 401 Spirometer, reusable mouth piece and nose clip were used for the test. Each subject was asked to perform the FVC test three times after a rest of 1-2 minutes. The best manoeuvre was selected.

2.3. Data Analysis. All statistical analyses were performed using SPSS 16 for Windows (Statistical Products and Service Solutions, Inc., Chicago). For testing differences between the means, we used Student's $t$-test or analysis of variance. In all statistical tests the confidence interval (CI) was 95\% and $P<0.05$ (two tailed) was considered as significant. The ANOVA test was used for testing differences in the prevalence of respiratory symptoms between groups.

2.4. Dust Sampling. Respirable suspended particulate matter various sections were measured by SKC Leland Legacy pump on $2.0 \mu \mathrm{m}$ pore size PTFE (Teflon) filter at flow rate of 9.0 liters $/ \mathrm{min}$. The machine was attached to the worker and as such 20 dust samples were collected in four separate 


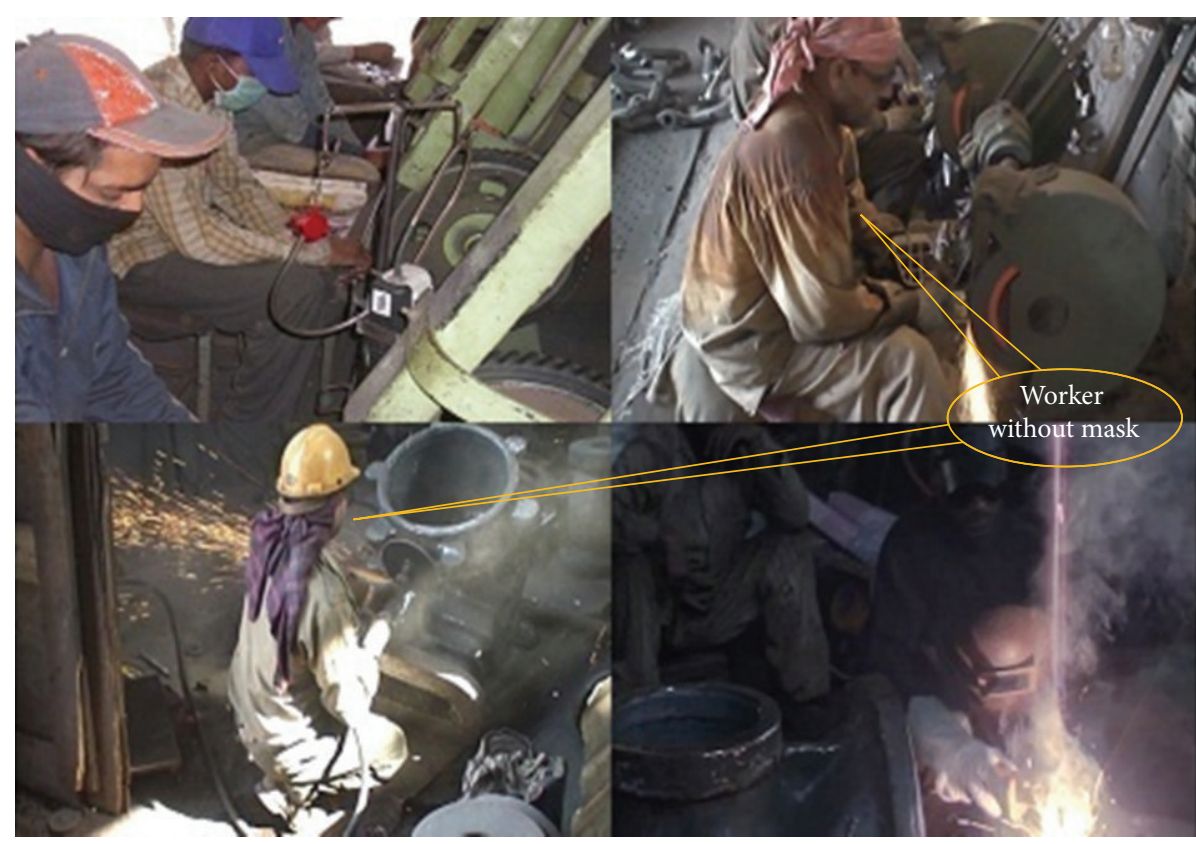

Figure 1: Working under dust and fumes at work places.

TABLE 1: Distribution of workers w.r.t. various health symptoms.

\begin{tabular}{lccc}
\hline Symptom & Total & Yes, $N(\%)$ & No, $N(\%)$ \\
\hline Phlegm & 572 & $254(44.41 \%)$ & $318(55.59 \%)$ \\
Wheezing & 572 & $242(38.46 \%)$ & $330(61.54 \%)$ \\
Breathless-ness & 572 & $240(40.21 \%)$ & $332(61.54 \%)$ \\
Asthma & 572 & $50(7.34 \%)$ & $522(92.66 \%)$ \\
\hline
\end{tabular}

areas in the plant over the 8-hour day work shift. Twenty dust samples were collected. Dust concentrations and time weighted average ( 8 hours) RSPM level are expressed, and the ranges are shown in milligrams per cubic meter (Table 1 ). The dust concentration was then derived as follows.

Calculations Used. Mass of particles found on the sample filter

$$
M_{s}=\left(M_{2}-M_{1}\right)
$$

where $M_{s}$ is the mass found on the sample filter, $M_{1}$ is the weight of the clean filter before sampling, mg, $M_{2}$ is the weight of the sample containing filter, mg, The sampled volume is

$$
V_{s}=Q \times \frac{T}{1000}
$$

where $V_{s}$ is the volume of the air sampled in $\mathrm{m}^{3}, \mathrm{Q}$ is the average flow rate of air sampled, $\mathrm{L} / \mathrm{min}, T$ is the sampling time, $\mathrm{min}, 1000$ is the conversion from $\mathrm{L}$ to $\mathrm{m}^{3}$.

The concentration of the particulate matter in the sampled air is expressed in micrograms $/ \mathrm{m}^{3}$

$$
C=\frac{M_{s}}{V_{s}},
$$

where $C=$ mass concentration of particulate matter, $\mathrm{mg} / \mathrm{m}^{3}$, $M_{s}=$ mass found on the sample filter in $\mathrm{mg}, V_{s}=$ volume of air sampled in $\mathrm{m}^{3}$.

\section{Results}

In case of the respiratory problems, around $49 \%$ of the workers reported coughing, $44 \%$ reported frequent phlegm, $38 \%$ reported wheezing, and $40 \%$ reported breathlessness, whereas asthma was reported by only $7 \%$ of the workers. These workers were from casting/moulding, gas cutting and welding, forging, grinding, and painting/nickel plating sections. The percentage of respiratory symptoms reported by workers is shown in Table 1.

3.1. Occupational Exposure with respect to RSPM. It is evident from Table 2 that the RSPM level was very high in moulding/casting and grinding sections whereas dust concentration is relatively lower in machining section. The RSPM level was above the prescribed limit of $5 \mathrm{mg} / \mathrm{m}^{3}$ by Indian factory act. It is pertinent to note that the workers were not using PPEs like masks; the workers working in various sections without proper masks are shown in Figure 1. Therefore a significant number of workers reported for respiratory symptoms.

3.2. Lungs Functions. The exposed group of industry subjects (workers) and control group of subjects were statistically comparable for mean age (SD) and mean work experience (SD) (at " $P$ " > 0.05). However the BMIs of exposed group subjects were significantly lower than the BMIs of control group. The $t$-test statics of mean age (SD) and mean work experience (SD) and mean BMIs (SD) of both the groups are also shown 
TABLE 2: RSPM level in various sections.

\begin{tabular}{|c|c|c|c|c|c|c|c|c|}
\hline $\begin{array}{l}\text { Name of } \\
\text { section/process }\end{array}$ & $\begin{array}{c}\text { Initial } \\
\text { weight of } \\
\text { filter }\left(M_{1}\right)\end{array}$ & $\begin{array}{l}\text { Final weight } \\
\text { of filter }\left(M_{2}\right)\end{array}$ & $\begin{array}{c}\text { Volume of air } \\
\text { sampled } \\
\text { (liters) }\end{array}$ & $\begin{array}{c}V_{s}=\text { volume } \\
\text { of air }\left(\mathrm{m}^{3}\right)\end{array}$ & $\begin{array}{l}\text { Net Wt of } \\
\text { dust (mg) }\end{array}$ & $\begin{array}{c}C=M / V \\
\left(\mathrm{mg} / \mathrm{m}^{3}\right)\end{array}$ & $\begin{array}{l}\text { Pump running } \\
\text { time (hrs) }\end{array}$ & $\begin{array}{c}\text { RSPM in } 8 \text { hrs } \\
\left(\mathrm{mg} / \mathrm{m}^{3}\right)\end{array}$ \\
\hline \multicolumn{9}{|c|}{ Punching/blanking/trimming section } \\
\hline Location 1 & 60.5 & 61.8 & 500 & 0.500 & 1.3 & 2.6 & 0.93 & 22.46 \\
\hline Location 2 & 59.2 & 60.6 & 495 & 0.495 & 1.4 & 2.83 & 0.92 & 24.68 \\
\hline Location 3 & 56.8 & 57.9 & 541 & 0.541 & 1.1 & 2.03 & 1.001 & 16.24 \\
\hline Location 4 & 58.9 & 60.2 & 516 & 0.516 & 1.3 & 2.52 & 0.96 & 21.09 \\
\hline Location 5 & 56.8 & 57.8 & 541 & 0.541 & 1 & 1.85 & 1.001 & 14.76 \\
\hline \multicolumn{9}{|c|}{ Forging section } \\
\hline Location 1 & 60.3 & 61.4 & 453 & 0.453 & 1.1 & 2.43 & 0.84 & 23.16 \\
\hline Location 2 & 57.8 & 58.9 & 516 & 0.516 & 1.1 & 2.132 & 0.96 & 17.85 \\
\hline Location 3 & 59.2 & 60.5 & 528 & 0.528 & 1.3 & 2.46 & 0.98 & 20.14 \\
\hline Location 4 & 59.2 & 60.4 & 510 & 0.51 & 1.2 & 2.35 & 0.94 & 19.93 \\
\hline Location 5 & 57.8 & 58.9 & 516 & 0.516 & 1.1 & 2.13 & 0.96 & 17.84 \\
\hline Location 6 & 60.1 & 61.4 & 541 & 0.541 & 1.3 & 2.40 & 1.001 & 19.18 \\
\hline \multicolumn{9}{|c|}{ Grinding section } \\
\hline Location 1 & 60.9 & 63.2 & 450 & 0.450 & 2.3 & 5.11 & 0.83 & 49.06 \\
\hline Location 2 & 59.6 & 61.8 & 450 & 0.450 & 2.2 & 4.89 & 0.83 & 46.93 \\
\hline Location 3 & 58.7 & 60.4 & 405 & 0.405 & 1.7 & 4.197 & 0.75 & 44.77 \\
\hline Location 4 & 58.2 & 60.6 & 516 & 0.516 & 2.4 & 4.65 & 0.96 & 38.93 \\
\hline Location 5 & 57.8 & 59.7 & 450 & 0.450 & 1.9 & 4.22 & 0.83 & 40.53 \\
\hline \multicolumn{9}{|c|}{ Polishing section } \\
\hline Location 1 & 57.1 & 59.7 & 554 & 0.554 & 2.6 & 4.69 & 1.026 & 36.59 \\
\hline Location 2 & 58.9 & 62.3 & 550 & 0.550 & 3.4 & 6.18 & 1.018 & 48.55 \\
\hline Location 3 & 59.5 & 61.9 & 550 & 0.550 & 2.4 & 4.36 & 1.018 & 34.27 \\
\hline Location 4 & 58.9 & 61.4 & 540 & 0.540 & 2.5 & 4.63 & 1 & 37.04 \\
\hline Location 5 & 58.5 & 61.3 & 560 & 0.560 & 2.8 & 5.00 & 1.037 & 38.57 \\
\hline \multicolumn{9}{|c|}{ Moulding/casting section } \\
\hline Location 1 & 58.6 & 61.9 & 550 & 0.55 & 3.3 & 6.00 & 1.018 & 47.12 \\
\hline Location 2 & 57.7 & 60.2 & 532 & 0.532 & 2.5 & 4.7 & 0.985 & 38.15 \\
\hline Location 3 & 59.2 & 61.4 & 534 & 0.534 & 2.2 & 4.12 & 0.99 & 33.33 \\
\hline Location 4 & 58.9 & 61.3 & 580 & 0.580 & 2.4 & 4.14 & 1.074 & 30.82 \\
\hline Location 5 & 59.2 & 62.2 & 590 & 0.590 & 3 & 5.08 & 1.092 & 37.23 \\
\hline \multicolumn{9}{|c|}{ Broaching/marching section } \\
\hline Location 1 & 60.1 & 61.4 & 580 & 0.580 & 1.3 & 2.24 & 1.074 & 16.69 \\
\hline Location 2 & 58.7 & 60.1 & 590 & 0.590 & 1.4 & 2.37 & 1.092 & 17.37 \\
\hline Location 3 & 59.6 & 61.2 & 650 & 0.65 & 1.6 & 2.46 & 1.204 & 16.35 \\
\hline Location 4 & 58.6 & 59.4 & 545 & 0.545 & 0.8 & 1.46 & 1.009 & 11.63 \\
\hline Location 5 & 58.6 & 59.5 & 541 & 0.541 & 0.9 & 1.66 & 1.001 & 13.28 \\
\hline \multicolumn{9}{|c|}{ Tool room section } \\
\hline Location 1 & 57.3 & 58.2 & 511 & 0.511 & 0.9 & 1.76 & 0.946 & 14.88 \\
\hline Location 2 & 57.3 & 58.3 & 584 & 0.584 & 1 & 1.71 & 1.081 & 12.67 \\
\hline Location 3 & 58.6 & 59.5 & 570 & 0.570 & 0.9 & 1.57 & 1.056 & 11.96 \\
\hline Location 4 & 57.6 & 58.5 & 565 & 0.565 & 0.9 & 1.59 & 1.046 & 12.17 \\
\hline Location 5 & 56.6 & 57.5 & 554 & 0.554 & 0.9 & 1.62 & 1.025 & 12.67 \\
\hline \multicolumn{9}{|c|}{ Electroplating/painting section } \\
\hline Location 1 & 58.4 & 59.5 & 630 & 0.630 & 1.1 & 1.75 & 1.167 & 11.97 \\
\hline Location 2 & 58.6 & 59.9 & 620 & 0.620 & 1.3 & 2.096 & 1.148 & 14.60 \\
\hline Location 3 & 57.3 & 58.2 & 590 & 0.590 & 0.9 & 1.53 & 1.093 & 11.16 \\
\hline Location 4 & 58.6 & 59.2 & 545 & 0.545 & 0.6 & 1.101 & 1.009 & 8.726 \\
\hline \multicolumn{9}{|c|}{ Gas cutting/welding section } \\
\hline Location 1 & 58.4 & 60.2 & 630 & 0.630 & 1.8 & 2.85 & 1.167 & 19.59 \\
\hline Location 2 & 59.6 & 61.7 & 620 & 0.620 & 2.1 & 3.38 & 1.15 & 23.60 \\
\hline Location 3 & 58.5 & 60.1 & 590 & 0.590 & 1.6 & 2.72 & 1.09 & 19.85 \\
\hline Location 4 & 56.6 & 58.7 & 650 & 0.650 & 2.1 & 3.23 & 1.20 & 21.47 \\
\hline
\end{tabular}


TABLE 3: Student's $t$-test statics of lung functions of exposed group v/s control group.

\begin{tabular}{|c|c|c|c|c|}
\hline Parameter & $\begin{array}{l}\text { Exposed group } \\
\quad(N=309) \\
\text { mean } \\
\text { Std. deviation }\end{array}$ & $\begin{array}{l}\text { Control group } \\
(N=74) \text { mean } \\
\text { Std. deviation }\end{array}$ & Mean difference & " $P$ " value \\
\hline Age & $31.28(9.12)$ & $29.36(6.30)$ & 1.91022 & 0.089 \\
\hline BMI & $22.45(3.30)$ & $22.05(2.53)$ & .39264 & 0.339 \\
\hline FVC & $3.46(0.60)$ & $3.82(0.67)$ & -.35855 & 0.001 \\
\hline $\mathrm{FEV}_{1}$ & $2.72(0.53)$ & $3.32(0.56)$ & -.59251 & 0.001 \\
\hline $\mathrm{FEV}_{1} / \mathrm{FVC}$ ratio & 78.65 (8.79) & $87.25(10.08)$ & -8.59914 & 0.001 \\
\hline $\mathrm{FEF}_{25-75}$ & $2.60(0.99)$ & $3.86(1.15)$ & -1.26551 & 0.001 \\
\hline PEFR & $6.93(1.64)$ & $7.73(1.66)$ & -.80842 & 0.001 \\
\hline FIVC & $2.98(0.79)$ & $3.37(0.80)$ & -.39534 & 0.000 \\
\hline PIFR & $3.68(1.40)$ & $4.55(1.53)$ & -.87481 & 0.001 \\
\hline
\end{tabular}

in Table 3. As the results shows that spirometric parameters such as FVC, $\mathrm{FEV}_{1}$, and $\mathrm{FEV}_{1} / \mathrm{FVC}$ ratio, $\mathrm{FEF}_{25-75}, \mathrm{PEFR}$, PIFRs and FIVC are lower in exposed group than controls. The lowering in $\mathrm{FVC}, \mathrm{FEV}_{1}$, and $\mathrm{FEV}_{1} / \mathrm{FVC} \%$ suggests a combination of obstructive and restrictive patterns in their lungs. This reduction in their lung functions could possibly be associated with exposure to dust. Hence the industry workers showed significantly lower lung function values $\mathrm{FVC}, \mathrm{FEV}_{1}$, and $\mathrm{FEV}_{1} / \mathrm{FVC}$ ratio, $\mathrm{FEF}_{25-75}$, PEFR, PIFR, and FIVC as compared to the control group at $P<0.01$.

3.3. Effect of Occupation on Lung Functions. As shown in Table 4, there is significant difference (at $P<0.05$ ) between the lung function parameters (FVC, $\mathrm{FEV}_{1}, \mathrm{FEV}_{1} / \mathrm{FVC} \%$, $\mathrm{FEF}_{25-75}$, PEFR, PIFR, and FIVC) of industry subjects engaged in various sections. The values are significantly (at $P<0.05)$ lower in workers working in grinding and moulding sections. The lowering in $\mathrm{FVC}, \mathrm{FEV}_{1}$, and $\mathrm{FEV}_{1} / \mathrm{FVC} \%$ suggests a combination of obstructive and restrictive patterns in their lungs. Post hoc Tuky's analysis for multiple comparisons reveals that there is insignificant difference of body mass index (BMI) among the various subgroups of subjects engaged in various sections including the control group subjects. However, age is significantly verifying among some of the subgroups. As far as the variation of lung functions within the exposed group is concerned, workers of grinding section showed significantly lower value of FVC as compared to the control subjects; however there is insignificant difference from the workers of other sections. Forging workers are also found be significantly lower FVC as compared to control subject. There is insignificant difference of $\mathrm{FEV}_{1}$ among the various sections within the exposed group, at the same time it is significantly lower as compared to control subjects for all sections except the workers of electroplating section. Within the exposed group, the workers of moulding/casting process are found with significantly lower $\mathrm{FEV}_{1} / \mathrm{FVC}$ ratio as compared to forging section, although all other sections are found with insignificant difference of $\mathrm{FEV}_{1} / \mathrm{FVC}$ ratio among each other (at $P<0.05$ ). The subjects of all sections of exposed group are having significantly lower $\mathrm{FEV}_{1} / \mathrm{FVC}$ ratio and $\mathrm{FEF}_{25-75}$ as compared to control subjects. It is also evident from the results that within the exposed group subjects, there is insignificant difference of PEFR, FIVC, and PIFR. However the workers of grinding and moulding sections are having significantly lower value of PEFR, FIVC, and PIFR as compared to control group.

Over all it is clear from the data analysis that the workers engaged in moulding and grinding sections are found with significantly lower values of all the lung function parameters as compared to control group. However all sections exposed group are found with significantly (at $P<0.05$ ) lower $\mathrm{FEV}_{1}$, $\mathrm{FEV}_{1} / \mathrm{FVC}$ and $\mathrm{FEF}_{25-75}$ values as compared to control group.

For this Tukey's post hoc test showed that G9 (control subgroup) has significant difference from all the other subgroups. As G9 subgroup includes controls and groups G1 to G8 includes workers working in different sections of casting and forging industry. So it is clear that the significant difference is due to the fact that workers are exposed to high levels of dust, high ambient air temperatures, and high relative humidities as compared to controls.

\section{Discussion}

Results reveal that all the spirometric values such as FVC, $\mathrm{FEV}_{1}, \mathrm{FEV}_{1} / \mathrm{FVC}$ ratio, $\mathrm{FEF}_{25-75}, \mathrm{PEFR}, \mathrm{FIVC}$, and PIFR in exposed group than in the control group. Other studies also reported lower FVC, $\mathrm{FEV}_{1}, \mathrm{FEV}_{1} / \mathrm{FVC}$ ratio, PEFR, and PIFR $[4,7-9]$. The lowering in FVC, $\mathrm{FEV}_{1}$, and $\mathrm{FEV}_{1} / \mathrm{FVC} \%$ suggests a combination of obstructive and restrictive patterns in their lungs. The lowering in $\mathrm{FEF}_{25-75}$ also causes an airway obstruction as it gives an indication of what is happening in the lower airways. The decrease in PEFR and PIFR is an indicator of restrictive lung disease. These results are in accordance with the results given by Mustajbegovic et al. [12] and Yanev [13]. In the present study, the reduction in lung functions could possibly be associated with exposure to dust as the respirable dust levels obtained were considerably higher than the recommended levels. The workers were also exposed to high ambient air temperatures as well as to relative humidity. Another reason for this is that the workers working in forging 


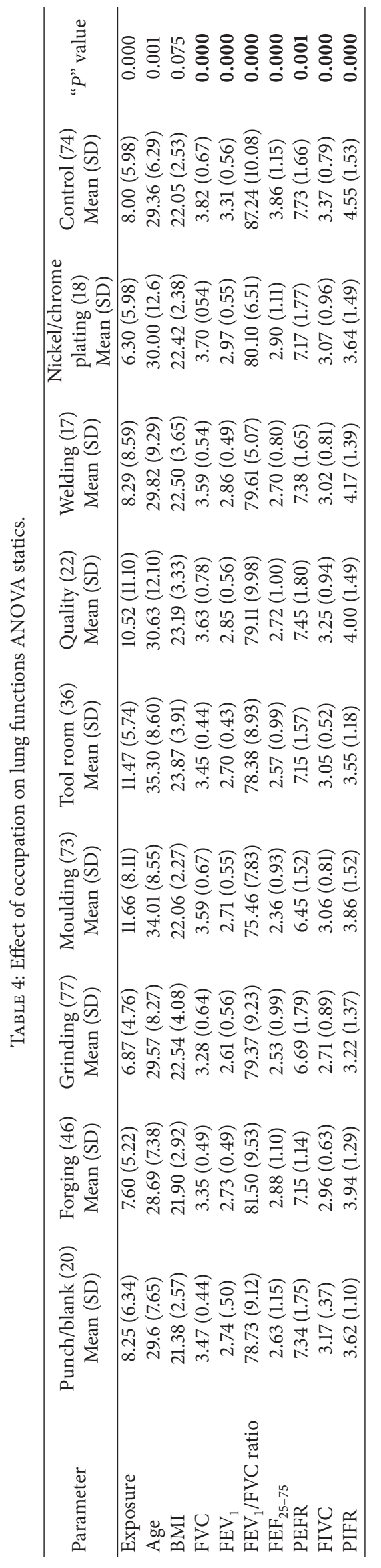


and casting industry are not wearing proper protective equipment. Our results are in accordance with Gomes et al. [14] and Oxman et al. [15]. Singhal et al. [10] they have also reported a significant reduction in expiratory and inspiratory flow rates, that is, PEFR, PIFR, $\mathrm{FEF}_{25-75}$, and $\mathrm{FIF}_{50}$. Reduction in PEFR otherwise showed a classic pattern of restrictive lung disease. The flow rates at low volumes, that is, $\mathrm{FEF}_{25-75}$ and $\mathrm{FIF}_{50}$, indicate flow rates in small airways, that is, those with internal diameters of less than $2 \mathrm{~mm}$. These are reduced at low lung volumes both in restrictive and obstructive diseases. Tiwari et al. [3] reported that lung function measurements, even after adjusting for age, weight, and smoking habits, were significantly lower in the silica dust exposure group than in the control group. Mikov [11] showed that the mean FEV, of foundry workers was considerably lower than that of a control group irrespective of the smoking habit.

4.1. Effect of Occupation on Lung Function. Lung function parameters were also found to be associated with occupation; the results revealed that almost all lung functions parameters were lower in workers working in grinding and moulding/casting sections were significantly lower than the control group subjects. The lowering in FVC, FEV1, and FEV1/FVC\% ratio suggests a combination of obstructive and restrictive patterns in their lungs. The reason for the same attributed to significantly higher RSPM level was higher in moulding/casting and grinding sections. The workers were also exposed to high ambient air temperatures as well as to relative humidities that were higher. Another reason for this is that the workers were not wearing proper protective equipment as reported in Singh et al. [16]. The workers engaged in moulding/casting sections were reluctant to wear the nose/mouth mask, as reported in subjective responses. The reason is that the workers of moulding/casting sections are doing heavy activities at higher metabolic rate; thus they require fast respiration and the mask they are using causes difficulty in breathing and make them uncomfortable.

\section{Conclusions}

Results reveal that all the spirometric values such as FVC, $\mathrm{FEV}_{1}, \mathrm{FEV}_{1} / \mathrm{FVC}$ ratio, $\mathrm{FEF}_{25-75}, \mathrm{PEFR}, \mathrm{FIVC}$, and PIFR were lower among the industrial workers than the controls. Lung function parameters were also found to be associated with occupation, all lung parameters were significantly lower in workers engaged in grinding and moulding/casting sections as compared to control group subjects.

The workers engaged in moulding/casting sections were reluctant to wear the nose/mouth mask. The reason is that the workers of moulding/casting sections are doing heavy activities at higher metabolic rate; thus they require fast respiration and the mask they are using causes hindrance in breathing and makes them uncomfortable. The other reason might be the quality of masks; therefore, it is recommended that mask of adequate quality should be provided to the workers.

\section{Key Points}

(1) The study shows alarming signals of lung function deterioration among the industry workers.

(2) The workers engaged in moulding/casting sections were reluctant to wear the nose/mouth mask.

(3) The reason is that the workers of moulding/casting sections are doing heavy activities at higher metabolic rate; thus they require fast respiration and the mask they are using causes hindrance in breathing and makes them uncomfortable.

(4) The other reason might be the quality of masks; therefore, it is recommended that masks of adequate quality should be provided to the workers.

\section{Conflict of Interests}

It is hereby clarified that none of the authors of the paper, has any direct/indirect financial relation with the software and corporation mentioned in the paper.

\section{Acknowledgments}

The authors acknowledge the cooperation and help extended by the managements of the casting and forging SMEs for collecting the qualitative information and providing the workers. The authors also acknowledge the volunteer participation and co-operation extended by the workers.

\section{References}

[1] P.-C. Chen, P. E. Doyle, and J.-D. Wang, "Respirable dust exposure and respiratory health in male Taiwanese steelworkers," Industrial Health, vol. 44, no. 1, pp. 190-199, 2006.

[2] Y. I. A. Neaimi, J. Gomes, and O. L. Lloyd, "Respiratory illness and ventilator function among workers at a cement factory in a rapidly developing country," Occupational Medicine, vol. 51, no. 6, pp. 367-373, 2001.

[3] R. R. Tiwari, R. Narain, B. D. Patel, I. S. Makwana, and H. N. Saiyed, "Spirometric measurements among quartz stone exworkers of Gujarat, India," Journal of Occupational Health, vol. 45, no. 2, pp. 88-93, 2003.

[4] J. W. Koo, C. K. Chung, C. Y. Park et al., "The effect of silica dust on ventilatory function of foundry workers," Journal of Occupational Health, vol. 42, no. 5, pp. 251-257, 2000.

[5] Y. W. Law, M. C. Leung, C. C. Leung, T. S. Yu, and C. M. Tam, "Characteristics of workers attending the pneumoconiosis clinic for silicosis assessment in Hong Kong: retrospective study," Hong Kong Medical Journal, vol. 7, no. 4, pp. 343-349, 2001.

[6] G. Ostiguy, C. Vaillancourt, and R. Begin, "Respiratory health of workers exposed to metal dusts and foundry fumes in a copper refinery," Occupational and Environmental Medicine, vol. 52, pp. 204-210, 1995.

[7] E. Zuskin, J. Mustajbegovic, E. N. Schachter, J. Kern, J. Doko, and J. Godnic-Cvar, "Respiratory findings in workers employed in the brick-manufacturing industry," Journal of Occupational and Environmental Medicine, vol. 40, no. 9, pp. 814-820, 1998. 
[8] F. Dehghan, S. Mohammadi, Z. Sadeghi, and M. Attarchi, "Respiratory complaints and spirometric parameters in tile and ceramic factory workers," Tanaffos, vol. 8, no. 4, pp. 19-25, 2009.

[9] J. E. Myers and J. E. Cornell, "Respiratory health of brickworkers in Cape Town, South Africa. Symptoms, signs and pulmonary function abnormalities," Scandinavian Journal of Work, Environment and Health, vol. 15, no. 3, pp. 188-194, 1989.

[10] M. Singhal, F. Khaliq, S. Singhal, and O. P. Tandon, "Pulmonary functions in petrol pump workers: a preliminary study," Indian Journal of Physiology and Pharmacology, vol. 51, no. 3, pp. 244248, 2007.

[11] M. I. Mikov, "Chronic bronchitis in foundry workers in Vojvodina. Ventilatory capacity in foundry workers," Archives of Environmental Health, vol. 29, no. 5, pp. 261-267, 1974.

[12] J. Mustajbegovic, E. Zuskin, E. N. Schachter, J. Kern, M. Luburic-Milas, and J. Pucarin, "Respiratory findings in tobacco workers," Chest, vol. 123, no. 5, pp. 1740-1748, 2003.

[13] I. Yanev, "Dynamic study of respiratory functions in tobacco workers," Folia Medica, vol. 29, no. 3, pp. 33-41, 1987.

[14] J. Gomes, O. L. Lloyd, N. J. Norman, and P. Pahwa, “Dust exposure and impairment of lung function at a small iron foundry in a rapidly developing country," Occupational and Environmental Medicine, vol. 58, no. 10, pp. 656-662, 2001.

[15] A. D. Oxman, D. C. F. Muir, H. S. Shannon, S. R. Stock, E. Hnizdo, and H. J. Lange, "Occupational dust exposure and chronic obstructive pulmonary disease: a systematic overview of the evidence," The American Review of Respiratory Disease, vol. 148, no. 1, pp. 38-48, 1993.

[16] L. P. Singh, A. Bhardwa, K. K. Deepak, and S. Sahu, "Small and medium scale casting and forging industry in India: an ergonomic study," Ergonomics Society of South Africa, vol. 22, no. 1, pp. 36-56, 2010. 


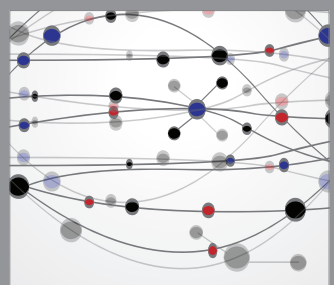

The Scientific World Journal
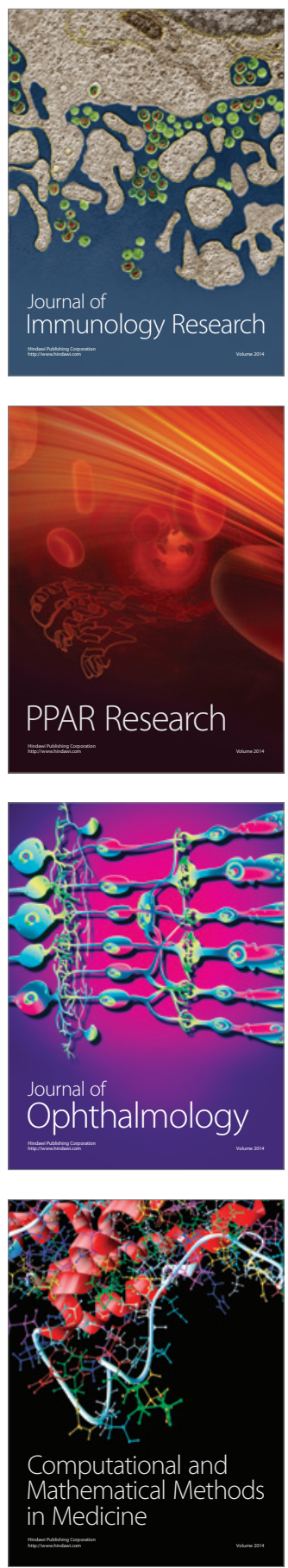

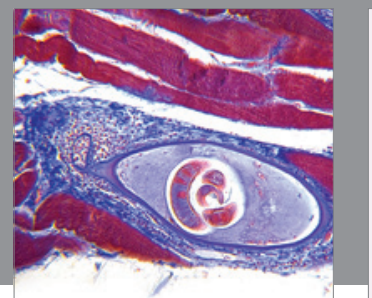

Gastroenterology

Research and Practice
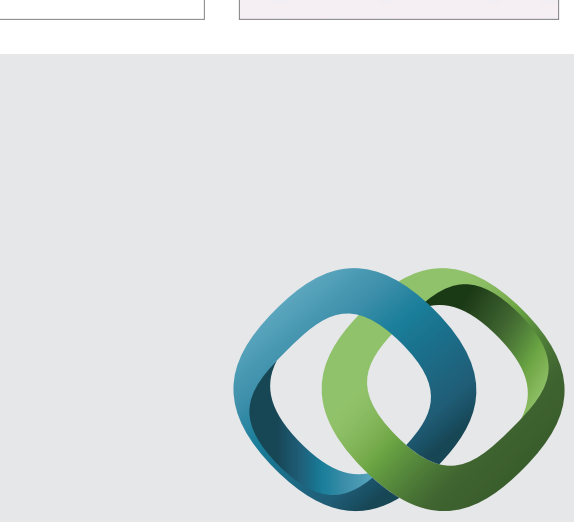

\section{Hindawi}

Submit your manuscripts at

http://www.hindawi.com
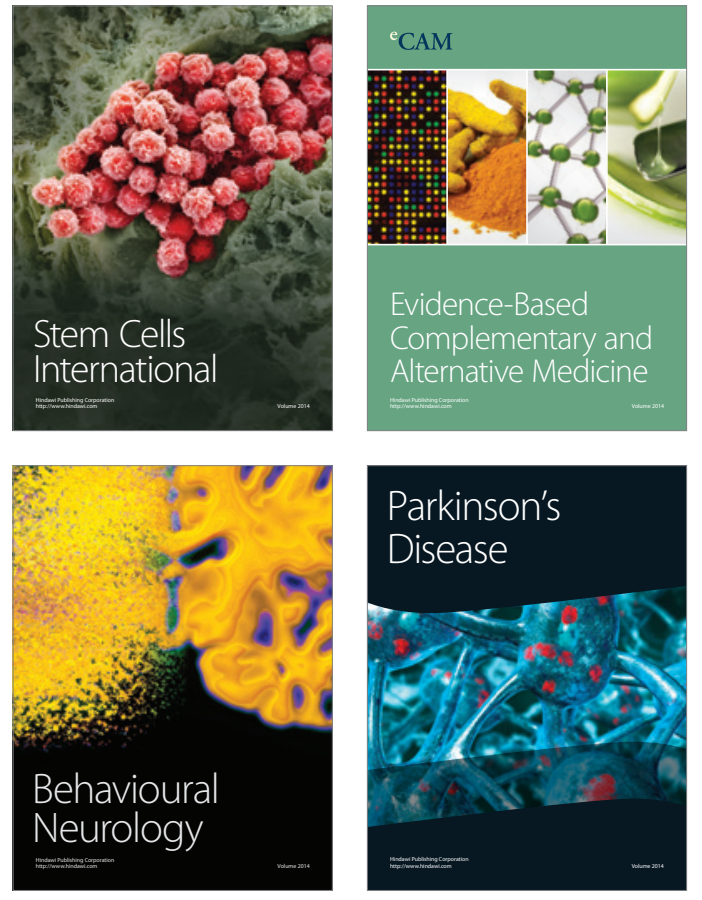
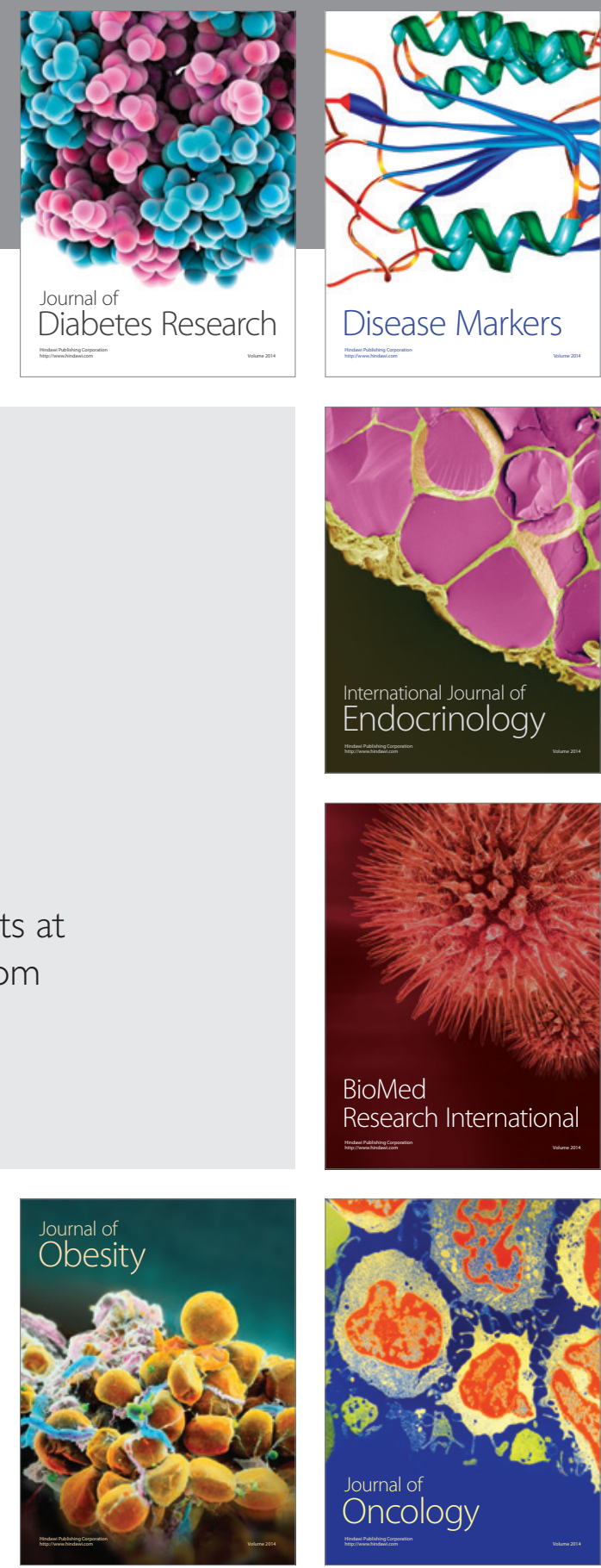

Disease Markers
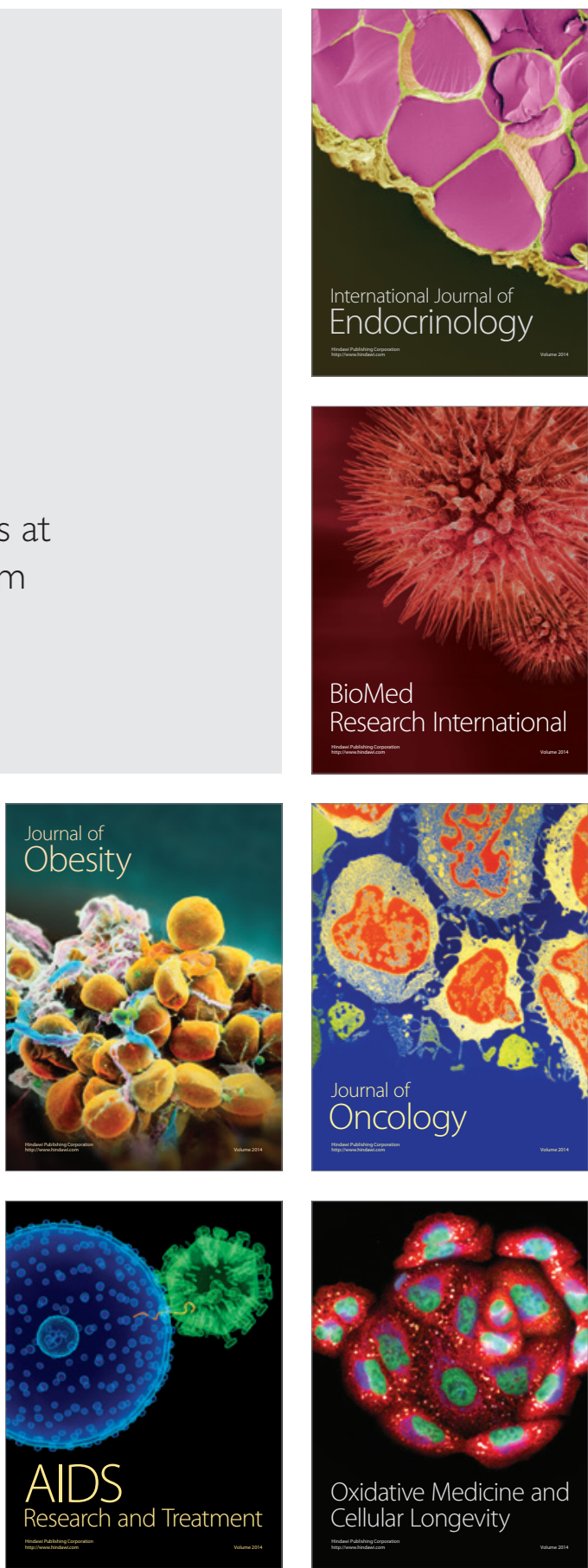